\section{Tempos modernos do direito medieval}

Harold BERMAN. Direito e revolução: a formação da tradição jurídica ocidental. São Leopoldo, Editora Unisinos, 2006. 707 páginas.

\section{Bernardo Ferreira}

Não representa nenhuma novidade afirmar que o processo de institucionalização das ciências sociais no Brasil tem sido acompanhado de uma crescente especialização disciplinar. Sob diversos aspectos, essa especialização se impõe pelas próprias condições de um trabalho intelectual sério. Não é difícil enumerar, um pouco arbitrariamente, alguns dos fatores que levam a essa direção: o volume crescente da produção bibliográfica nos diferentes campos do saber e nas diferentes temáticas, a multiplicação e progressiva especificação dos objetos de pesquisa, a exigência de uma qualificação técnica adequada, a disseminação de redes de investigação em torno de problemas particulares e - por que não? - os limites humanos dos próprios estudiosos conduzem à especialização e fazem dela um fator fundamental do desenvolvimento da pesquisa acadêmica. Outra coisa, no entanto, é o isolamento e a ausência de comunicação entre as diferentes áreas do conhecimento que têm acompanhado o processo de institucionalização e a tendência à especialização. Para não falar da compreensão demasiado estreita e, freqüentemente, corporativa das fronteiras e diferenças disciplinares. Uma compreensão que corre o risco de reificar a atual partilha dos saberes, ignorando o que há de historicamente condicionado nas diferenciações entre os campos do conhecimento com que estamos acostumados.

As dificuldades de diálogo que decorrem desse tipo de perspectiva podem se tornar ainda maiores, quando está em jogo o intercâmbio entre as ciências sociais e as demais áreas que integram o campo que, grosso modo, denominamos humanidades. Essa é, em certa medida, a situação dos estudos no campo jurídico. $\mathrm{O}$ ensino e a pesquisa no âmbito do Direito e das ciências sociais constituem mundos cujo contato é muito mais descontínuo e intermitente do que se poderia esperar. A título de exemplo: não é incomum que pesquisas relevantes, obras significativas e traduções de textos importantes acabem por circular privilegiadamente no âmbito do mercado das editoras e livrarias jurídicas, sem que, muitas vezes, os profissionais de áreas afins tenham sequer notícia de sua existência. Há, naturalmente, razões de parte a parte que contribuem para esse estado de coisas. Para além do enrijecimento das fronteiras disciplinares decorrente do processo de institucionalização e especialização, é possível supor que, no caso específico do Direito, a posição tradicional da educação jurídica no país - a qual, durante o século XIX e parte do XX, foi praticamente sinônima de ensino universitário tenha contribuído para o isolamento da disciplina dentro de um circuito relativamente fechado. Acrescentem-se a isso os aspectos técnicos que distinguem a formação de um jurista e a feição marcadamente instrumental que tem caracterizado os cursos universitários de Direito.

Direito e revolução: a formação da tradição jurídica ocidental [Law and revolution: the formation of Western legal tradition], recém-traduzido para o português pela Editora Unisinos, vai na contramão dessas tendências. Publicado em 1983 - quando o seu autor, Harold Berman (1918-2007), já era um reconhecido especialista em direito soviético da Harvard Law School -, o texto procura reconstruir a história do direito ocidental no período da Reforma Gregoriana, movimento de reestruturação da Igreja medieval ocorrido entre a segunda metade do século XI e o século XII e cujo nome está associado a seu principal protagonista, o papa Gregório VII. Para compreender as transformações ocorridas nesse período, observa o autor, seria preciso se afastar de "uma visão por demais estreita do direito", que o restringiria a "um conjunto de leis, procedimentos, normas administrativas e técnicas válidas em um determinado país” (p. 9). Essa perspectiva, ao estabelecer uma identidade entre o direito e uma ordem normativa positivada, teria capacidade limitada de dar conta dos processos pelos quais uma ordem jurídica adquire efetividade social e realidade histórica. Daí a necessidade de sublinhar a "primazia da atividade jurídica sobre as suas regras" (p. 15), deslocando a ênfase para o "processo dinâmico de atribuir direitos e deveres e, assim, resolver conflitos e 
criar canais de cooperação" (p. 15). Dentro desse horizonte mais amplo, acredita o autor, seria possível conferir ao direito profundidade histórica e densidade social e, ao mesmo tempo, abrir a via para um tipo de pesquisa que não ficasse presa aos limites da compartimentação disciplinar.

Dessa forma, Berman se propõe reconstruir o processo histórico de formação dos traços distintivos do direito ocidental ou, para ser mais preciso, do que ele denomina de Tradição Jurídica Ocidental. Segundo ele, no período anterior ao século XI não existia, tanto no âmbito eclesiástico como no secular, "uma clara separação entre o direito e outros processos de controle social e de outros tipos de preocupação intelectual" (p. 111). Nesse contexto, a ordem jurídica não se diferenciava dos costumes sociais e das instituições políticas e religiosas. Ainda que existissem concepções, normas e procedimentos jurídicos, o direito não existia como um sistema estruturado, ou seja, como um corpo articulado de princípios, instituições e práticas, dotados de independência em relação a outras esferas da vida social. As transformações ocorridas com a Reforma Gregoriana teriam um caráter inaugural, porque, com elas, o direito "tornou-se autônomo" (p. 112). Essa autonomia seria um resultado do esforço - iniciado no século X com o movimento monástico de Cluny e radicalizado com a reforma dos séculos XI e XII - de estabelecer uma clara separação entre as esferas temporal e espiritual, o mundo dos clérigos e o dos leigos, e, simultaneamente, afirmar a independência das autoridades eclesiásticas em face dos poderes seculares. A busca da libertas ecclesia (liberdade da Igreja) por parte dos reformadores foi, segundo Berman, inseparável do recurso ao direito. Como ele observa, "a Igreja lançou-se à reforma tanto de si mesma quanto do mundo por intermédio do direito" (p. 102, tradução modificada). Dessa forma, a Igreja veio a ser concebida, para além da sua unidade espiritual e doutrinária, como uma comunidade de natureza jurídica, como um corpo coletivo estruturado em torno de uma autoridade centralizada e dotada de competência legislativa e jurisdicional. A expressão política mais evidente desse fato foi a tentativa de instituir uma monarquia papal no interior da Igreja, resultante da supremacia jurisdicional do governo do bispo de Roma sobre o conjunto da comunidade eclesiástica.

A contraface secular desse esforço de separação entre a esfera temporal e a espiritual e de concomitante afirmação da independência do clero em relação às autoridades não eclesiásticas foi o progressivo esvaziamento do significado sagrado da realeza. No período anterior à Reforma Gregoriana, a realeza era compreendida em termos da sua função no interior da Igreja e estava revestida de um caráter sagrado. O movimento de reforma ao reivindicar para o clero a exclusividade das funções espirituais procurou despojar reis e imperadores de seu papel eclesiástico e reduzi-los a uma condição meramente profana. Com isso, as transformações iniciadas na segunda metade do século XI fizeram "surgir, pela primeira vez, entidades políticas desprovidas de funções eclesiásticas e ordens jurídicas não eclesiásticas” (p. 345, tradução modificada).

No interior da Igreja, um dos principais desdobramentos dessas mudanças foi o surgimento do Direito Canônico como um sistema articulado de regras jurídicas, diferenciadas da liturgia e da teologia. Segundo Berman, até o século XI, "havia normas eclesiásticas, uma ordem jurídica no âmbito da Igreja, mas nenhum sistema de direito eclesiástico" (p. 259, tradução modificada). O movimento de reforma teria desencadeado um esforço de sistematização e racionalização das normas que deveriam reger a vida na Igreja como um corpo jurídico. Com o Direito Canônico, forma-se, afirma o autor, "o primeiro sistema jurídico ocidental moderno". ${ }^{1}$ Como conseqüência da separação entre a esfera secular e a eclesiástica, desenvolveram-se, por meio de um movimento de emulação e rivalidade em face do Direito Canônico, uma série de sistemas jurídicos de natureza não eclesiástica. Enquanto o direito da Igreja apresentava um caráter unitário, o direito secular tinha uma feição plural, distinguindo-se em diversos sistemas: feudal, senhorial, mercantil, urbano e régio.

As mudanças ocorridas a partir o século XI ao buscarem estabelecer uma nítida distinção entre o sagrado e o profano, entre o espiritual e o temporal, entre ordem eclesiástica e ordem laica - teriam dividido o Ocidente medieval em duas partes, a Igreja e a esfera secular (cf. p. 655). Dessa forma, 
observa Berman, teriam introduzido um "dualismo entre as jurisdições secular e eclesiástica” e, como resultado, "a coexistência e a competição, na mesma comunidade, de várias jurisdições e sistemas jurídicos" (p. 21). Ambos os traços constituiriam características distintivas, se não únicas, da cultura ocidental (cf. p. 59). Nesse sentido, o recuo aos anos da Reforma Gregoriana se imporia a todos aqueles interessados em pensar a trajetória peculiar dessa cultura. O termo Ocidente, diz o autor, não se confundiria com uma unidade geográfica, mas buscaria dar conta de uma espécie de identidade cultural e civilizatória, marcada por "uma forte dimensão diacrônica" (p. 12). Daí a necessidade de ir além de uma concepção do direito que o reduziria à ordem legal instituída numa dada nação, esvaziando a profundidade histórica da tradição jurídica do Ocidente. A compreensão da especificidade do direito ocidental implicaria, portanto, uma abordagem que ultrapassasse as fronteiras nacionais e reconhecesse que, "no Ocidente, os tempos modernos [...] deitam suas raízes no período de 1050-1150, e não antes" (p. 14).

Para dar conta da transformação fundamental que teria ocorrido nesse período, o livro está dividido em duas partes. A primeira dedicada às alterações no interior da Igreja decorrentes da Reforma Gregoriana e à emergência do Direito Canônico. A segunda voltada para a formação dos diferentes sistemas jurídicos seculares. Harold Berman realiza, em cada uma das partes, uma análise pormenorizada dos fatores envolvidos em processo de transformação histórica, em que o direito seria simultaneamente causa e efeito. Assim, o leitor trava contato com o surgimento das universidades, a constituição de um pensamento político de feição secular, as mudanças nas concepções sobre o tempo histórico e a vida no além, a expansão das relações feudais, o desenvolvimento dos vínculos senhoriais, o crescimento do comércio, a emergência da vida urbana, a progressiva afirmação da ordem estatal.

Ao recuar no tempo, remetendo o início da modernidade ocidental aos séculos XI e XII do mundo medieval, a narrativa de Harold Berman organiza-se, de um ponto de vista conceitual, a partir de dois eixos distintos. Esses eixos, embora não se encontrem claramente separados no texto, apre- sentam, a meu ver, rendimentos desiguais. Por um lado, existe uma narrativa sobre a passagem de uma ordem jurídica tradicional e de natureza não sistemática - em que o direito está imerso em um conjunto de práticas e representações religiosas e costumeiras - para outra ordem jurídica, mais próxima do que admitiríamos ser uma compreensão moderna - em que o direito se organiza como um sistema racionalizado e se apresenta como uma esfera autônoma da vida social. A noção de sistema jurídico e a sua diferenciação em relação à idéia mais geral de ordem jurídica são fundamentais na organização dessa narrativa. A partir desses conceitos, busca-se analisar como a autonomização do direito sob a forma de um sistema trouxe consigo uma série de mudanças: o surgimento de profissionais treinados em instituições voltadas para a transmissão de um conhecimento jurídico especializado, a constituição do direito como um todo coerente como um corpus juris - e que se desenvolve temporalmente segundo uma lógica interna, o surgimento de uma pluralidade de jurisdições e sistemas jurídicos. Ao lado dessa "primeira" narrativa, há outra, de caráter mais geral, que pressupõe a existência de uma Tradição Jurídica Ocidental, surgida com as transformações dos séculos XI e XII e integrada ao percurso histórico do Ocidente. Nessa "segunda" narrativa, o conceito de revolução desempenha um papel decisivo. Por meio dele, seria possível compreender a história do mundo ocidental moderno e da própria tradição jurídica a ele associada como o resultado de uma seqüência de episódios em que ocorreram mudanças abruptas, violentas, de alcance total e com conseqüências duradouras. Em cada uma dessas revoluções, as bases do direito ocidental seriam transformadas e, ao mesmo tempo, essas transformações se incorporariam a uma espécie de lastro anterior que acabaria por ser conservado. A Reforma Gregoriana teria sido a primeira das revoluções ocidentais; por isso, ela é denominada pelo autor de Revolução Papal. Nessa perspectiva, “a conseqüência mais importante da Revolução Papal foi a introdução na história ocidental da experiência da própria revolução” (p. 148). A essa primeira revolução ter-se-iam seguido cinco outros episódios revolucionários: a Reforma Protestante, a Revolução Inglesa do século XVII, a Revolução Americana, a 
Revolução Francesa e a Revolução Russa. Aos olhos do autor, estaríamos vivendo um momento de crise da Tradição Jurídica Ocidental, uma crise que se traduziria por um cinismo em relação ao direito e que, em última análise, se confundiria com uma perda de confiança da civilização ocidental em si mesma. Recontar as origens dessa tradição seria uma forma de buscar no passado elementos que permitissem interpelar a crise do presente. Trata-se, nos diz Berman, de um esforço de "apresentar a história do direito como uma metáfora de nosso tempo" (p. 10).

Nem sempre essa narrativa de caráter mais geral é convincente. Ao buscar na "Revolução Papal" um momento inaugural da história do Ocidente moderno, o autor é levado a estabelecer aproximações forçadas e, em certos momentos, anacrônicas. A começar pela idéia de que a Reforma Gregoriana constitui a primeira revolução ocidental. É preciso concordar com Harold Berman quando ele sublinha o caráter convencional da diferenciação entre Idade Média e Idade Moderna, insistindo em que uma estrita separação e descontinuidade entre os dois tempos nos tornaria incapazes de abordar satisfatoriamente uma série de temas históricos e, em particular, a história do direito. No entanto, o leitor, muitas vezes, fica com a impressão de que seria preciso introduzir elementos de mediação em algumas de suas análises sobre a modernidade das transformações ocorridas a partir do final do século XI. Mediações, enfim, que permitissem pensar de uma forma mais matizada não só as continuidades, mas também as descontinuidades no tempo.

É sempre bem-vinda a iniciativa de tradução de uma obra como essa. A editora Unisinos, ao levar a cabo essa tarefa, dá mostras de compreensão sobre o papel que as editoras universitárias podem desempenhar, no sentido de garantir o acesso em língua portuguesa a obras que, de outra forma, dificilmente encontrariam espaço no mercado editorial. É uma pena, no entanto, que a iniciativa não tenha sido acompanhada do cuidado editorial necessário. A tradução do livro apresenta inúmeros problemas, que vão desde imprecisões na versão de termos técnicos e nomes próprios, passando por erros de português, até incorreções que comprometem drasticamente o entendimento da leitura. Harold Berman chegou a publicar, em 2003, um segundo volume de Law and revolution (Law and revolution II. The impact of the protestant reformations on the Western Legal Tradition), no qual ele se volta para as transformações jurídicas decorrentes do movimento de reforma protestante e da Revolução Inglesa. Espera-se que, em breve, possamos dispor de uma versão desse segundo volume. Só que, dessa vez, com um pouco mais de atenção à qualidade do resultado editorial.

\section{Nota}

1 Esse é o subtítulo do capítulo 5 do livro.

BERNARDO FERREIRA é professor de Ciência Política do Departamento de Ciências Sociais da Universidade do Estado do Rio de Janeiro UERJ. E-mail: bferreira@openlink.com.br. 